\title{
$¿$ CRITERIOS UNIFICADOS COMO PRECEDENTES JUDICIALES EN MATERIA LABORAL? \\ (Revisión crítica de los fallos que acogen el recurso de unificación laboral entre marzo de 2008 y agosto de 2013)

\author{
United criterie as judicial precedents in labor? \\ (critical revision of decision that host the application of labor unification \\ between march 2008 and august 2013)
}

Samuel Soto Bustos *

Resumen: El presente trabajo, sobre la base de una noción moderada de precedente judicial vinculante, revisa si los criterios unificados, derivados de recursos de unificación de jurisprudencia laboral acogidos por la Corte Suprema chilena, han operado o se han constituido como precedentes judiciales vinculantes.

Palabras clave: Sistema legal - precedentes judiciales - recurso de unificación de jurisprudencia laboral.

\begin{abstract}
This paper, based on a moderated notion of binding judicial precedent, considers whether unified criteria derived from the Supreme Court of Chile's favorable rulings on recourses of labor jurisprudence unification have in fact operated as, or have created, binding judicial precedent.
\end{abstract}

Keywords: Legal system - judicial precedents - recourse of labor jurisprudence unification

\section{Introducción}

Es un hecho que el sistema de resolución judicial de conflictos laborales chileno sufrió, a partir del año 2005, un profundo cambio, tanto en lo orgánico, como en lo funcional. Podemos fijar claramente dos etapas en la modificación al sistema de enjuiciamiento laboral:

a. La primera etapa, o creación de la reforma procesal laboral, está marcada por la dictación y promulgación de las leyes $20.022,{ }^{1} 20.023^{2}$ y $20.087 .{ }^{3}$

\footnotetext{
* Abogado. Licenciado en Ciencias Jurídicas y Sociales, socio en Peralta, Soto, Urrutia Abogados. Correo electrónico:ssoto@psuabogados.cl

${ }^{1}$ La Ley 20.022, que creó nuevos Juzgados de Letras del Trabajo y Juzgados de Cobranza Laboral y Previsional en las comunas que indica, fue promulgada el 16 de mayo de 2005 y publicada el 30 de mayo de 2005. Esta ley suprimió los Juzgados del Trabajo existentes a la época y estableció Juzgados de Letras del Trabajo, con competencia en los territorios que el artículo número 1 de la misma, en las siguientes comunas: Arica, Iquique, Antofagasta, Copiapó, La Serena, Valparaíso, Rancagua, Curicó, Talca, Chillán Concepción, Temuco, Valdivia, Puerto Montt, Punta Arenas,
}

Este artículo fue recibido el 13 de septiembre de 2013, siendo aprobada su publicación con fecha 18 de noviembre de 2013. 
Soto - ¿Criterios unificados como precedentes judiciales en materia laboral?...

Esta fase significó muy resumidamente, el establecimiento de un nuevo sistema procesal laboral mediante el cual: se instauró un modelo de tribunal especializado distinto al existente; se pasó de un procedimiento inspirado, preponderantemente, en la escrituración a uno fundado, básicamente, en la oralidad; y, se creó un sistema de recursos que, en esencia, eliminó la intervención de la Corte Suprema en los procedimientos laborales ${ }^{4}$. Esta forma original no se instaló, pues antes de entrar en vigencia fue modificada de manera bien sustancial.

Santiago, San Miguel y San Bernardo. Asimismo creó Juzgados de Cobranza Laboral y Previsional en las comunas de Valparaíso, Concepción, San Miguel y Santiago.

El artículo 16 de la mencionada ley indicó que ella, en lo general, empezaría a regir el 1 de marzo de 2007 y ciertas materias nueve meses después de su publicación.

${ }^{2}$ La Ley 20.023, que modificó la Ley 17.322, el Código del Trabajo y el D.L. 3500 de 1980, fue promulgada el 16 de mayo de 2005 y publicada el 30 de mayo de 2005. Esta ley reformó, básicamente, las normas de cobranza de cotizaciones, aportes y multas de instituciones de seguridad social.

El artículo $1^{\circ}$ transitorio de la ley indicó que las normas modificatorias a la Ley 17.322 entrarían en vigencia conjuntamente con el inicio de funcionamiento de los Juzgados de Cobranza Laboral y Previsional y que la modificación que el artículo $3^{\circ}$ que la misma ley introduce al artículo 440 del Código del Trabajo entraría en vigencia el primer día del tercer mes siguiente al inicio de funcionamiento de los juzgados antes aludidos.

${ }^{3}$ La Ley 20.027, que sustituyó el procedimiento contemplado en el libro V del Código del Trabajo, fue promulgada el 15 de diciembre de 2005 y publicada el 3 de enero de 2006. Este texto legal hizo diversos cambios al Código del Trabajo, siendo los más importantes: el establecimiento de principios formativos del proceso y del procedimiento en juicio del trabajo; la creación de procedimientos declarativos orales (el de aplicación general, el de tutela laboral y el monitorio); una nueva regulación al procedimiento de cumplimiento de la sentencia y de ejecución de los títulos ejecutivos laborales, y el establecimiento de un sistema recursivo especial.

El artículo $1^{\circ}$ transitorio de esta ley expresó que ella entraría a regir el 1 de marzo de 2007.

${ }^{4} \mathrm{La}$ intervención de la Corte Suprema, en esta regulación, queda restringida al control de faltas o abusos cometidos en la dictación de resoluciones judiciales vía recurso de queja, pues la reglamentación de los recursos elimina la posibilidad de impugnar mediante casación en el fondo.

La afirmación que realizamos se sustenta en la norma del artículo 474 del Código del Trabajo, fijada por la Ley 20.087, que estableció "Los recursos se regirán por las normas establecidas en este Párrafo, y supletoriamente por las normas establecidas en el Libro Primero del Código de Procedimiento Civil”. De aquella disposición se entiende que el recurso de casación en el fondo era improcedente en materia laboral; ello en atención a que no se encuentra normado en el párrafo $5^{\circ}$ del capítulo II, del título I, del libro V del Código del Trabajo (Que reguló solo los recursos de reposición y apelación laboral) y ni en el Libro Primero del Código de Procedimiento Civil (Que se refiere a los recursos de rectificación, aclaración o enmienda, de reposición, de apelación y de hecho). A la razón de texto aludida, se une una razón histórica, pues la reglamentación anterior, y que la Ley 20.087 cambiaba, establecía, en el artículo 463 del Código del Trabajo, que "En los juicios laborales tendrán lugar los mismos recursos que proceden en los juicios ordinarios en lo civily se les aplicaran las mismas reglas en todo cuanto no se encuentra modificado por este párrafo".

En contra de la opinión señalada, la procedencia del recurso de casación en el fondo fue defendida por SILVA (2006), p. 53, indicando sobre el particular que aplicarían las reglas generales del Código de Procedimiento Civil, sin hacerse cargo del hecho que en materia de recursos el código del trabajo no remitía al libro Tercero del Código de Procedimiento Civil, en que se regula el recurso de casación. Un análisis que da cuenta de las razones que se podían dar en favor y en contra de la procedencia del recurso de casación en el fondo en materia laboral, a partir de la Ley 20.087, se puede encontrar en WALTER y LANATA (2007), pp. 155-157. 
b. La segunda etapa, o de perfeccionamiento e instalación de la reforma, se manifiesta en las leyes $20.164,{ }^{5} 20.252,{ }^{6} 20.260^{7}$ y $20.287 .{ }^{8}$ Es bastante evidente que el colapso del sistema de tribunales de familia, reforma procesal que sucedió a la reforma procesal penal y que antecedió a la reforma que nos ocupa, llevó a repensar si el diseño original sería capaz y eficiente para hacerse cargo de los requerimientos de justicia en un área tan sensible, como es el de los conflictos laborales. Es así como en esta etapa se posterga la entrada en vigencia de la reforma, primeramente desde el 1 de marzo de 2007 al 1 de marzo de 2008, manteniendo la idea de implementarla de manera simultánea en el país, para pasar luego a una entrada en vigencia gradual en el tiempo y el territorio nacional, que empieza el 31 de marzo de 2008 y culmina el 30 de octubre de 2009. Asimismo, y antes de la entrada en vigencia de la reforma laboral, se amplió el número de tribunales, de jueces y de funcionarios administrativos, para afrontar el requerimiento ciudadano de una justicia laboral rápida y eficiente. Por último, y con el fin de asegurar que el régimen procedimental asegurara los valores del derecho laboral sustantivo, se perfeccionaron los procedimientos y se modificó el sistema de recursos procesales, devolviendo a la Corte Suprema protagonismo en el sistema de resolución de conflictos laborales.

Con la aparición del recurso de unificación de jurisprudencia laboral se hizo la predicción que la entrega a la Corte Suprema de la competencia de unificar los criterios jurisprudenciales, implicaría un cambio significativo en las prácticas culturales de las Cortes de Apelaciones y de los tribunales de instancia.?

\footnotetext{
${ }^{5}$ La Ley 20.164, que postergó la entrada en vigencia de las leyes 20.022 y 20.087 al día 1 de marzo de 2008, fue promulgada el 2 de febrero de 2007 y publicada el día 14 del mismo mes y año.

${ }^{6}$ La Ley 20.252, que modificó la Ley 20.022 y otros cuerpos legales con el objeto de reforzar la judicatura laboral, se promulgó el 1 de febrero de 2008 y se publicó el 15 del mismo mes y año. Esta ley agrega nuevos tribunales especiales del trabajo y aumenta la planta de jueces y administrativos; así se crean tribunales de letras del trabajo en las comunas de Calama, San Felipe, Los Ángeles, Osorno, Castro y Coihayque; en Santiago se disminuyen de 3 a 2 los Juzgados de Letras del Trabajo, pero se aumenta el número de jueces total pasando de 17 a 26 . La ley modifica además la entrada en vigencia de la Ley 20.022, sustituyendo la entrada en vigencia desde el 1 de marzo de 2008 a un sistema gradual por regiones, partiendo el 31 de marzo de 2008 con las regiones III y XII y terminando en las regiones IX, X, XI y XV el 30 de octubre de 2009.

${ }^{7}$ La Ley 20.260, promulgada el 28 de marzo de 2008 y publicada el día 29 del mismo mes y año, modificó las normas de procedimiento laboral y modificó el sistema recursivo laboral, estableciendo como medios de impugnación disponibles, regulados especialmente por el código del ramo, los recursos de reposición, de apelación, de nulidad y de unificación de jurisprudencia.

${ }^{8}$ La Ley 20.287, promulgada el 1 de septiembre de 2008 y publicada el 17 del mismo mes y año, corrigió algunos defectos del procedimiento laboral en relación con exhortos, prueba documental y procedimiento de tutela.

9 En este sentido SILVA (2009), p. 56 indica "...Como quiera que en nuestra legislación general las sentencias judiciales sólo tienen fuerza obligatoria en las causas en que se pronuncia (art. $3^{\circ}$ del Código Civil, reiterado expresamente por el Código del Trabajo a propósito de esta materia), este recurso extraordinario, del que conocerá exclusivamente la Corte Suprema, dará en la práctica a las cortes de apelaciones y tribunales inferiores directrices y criterios de interpretación y aplicación de la legislación laboral. Difícilmente fallará un juez o una corte de alguna manera diversa de lo que vaya sosteniendo esta 'jurisprudencia unificada'..." (El subrayado es nuestro). Las afirmaciones de Silva Montes tenían como antecedente, por cierto, la discusión que se produjo en la tramitación de la ley donde el punto fue tocado, según se recoge en WALTER y
} 
Soto - ¿Criterios unificados como precedentes judiciales en materia laboral?...

La dictación del primer fallo que acoge un recurso de unificación de jurisprudencia en materia laboral, en la causa Ampuero Sánchez y otros con Agencia Maritima Alphamar S. A y Empresa Nacional del Petróleo ${ }^{10}$,dio lugar a un interesante artículo de Alejandro Romero Seguel ${ }^{11}$, en el que concluye que aquella sentencia inaugura el tránsito desde una jurisprudencia persuasiva a una jurisprudencia vinculante.

En un posterior trabajo, Romero Seguel ya habla derechamente del precedente judicial en el proceso laboral. ${ }^{12}$ Los alcances de la tesis de Romero Seguel se ven cuestionados, en algún sentido, por el trabajo de Delgado Castro y Díaz García quienes, sobre la base de lo que muestran algunos fallos, señalan la falta de cultura judicial para respetar las interpretaciones de la Corte Suprema en atención a que, a la época del estudio que ellos realizan, aparecen fallos de Cortes de Apelaciones que contradicen las doctrinas unificadas por nuestro máximo tribunal. ${ }^{13}$

Juntamente a los escritos antes citados, es posible encontrar, en la literatura jurídico laboral chilena, otros autores que se refieren al tema del precedente judicial a propósito del recurso de unificación de jurisprudencia laboral, ya cuestionando que la Corte Suprema se constituya en generador de precedentes, como también propugnado para que ella los cree en materias específicas de la regulación laboral. ${ }^{14}$

La literatura referida gira sobre una noción de precedente que no explica o evidencia; se satisface principalmente en desarrollos argumentativos; y, la referencia a los fallos de unificación dictados por la Corte Suprema, como asimismo a las sentencias de las Cortes de Apelaciones que son contrarios al criterio del tribunal superior, se realiza con el fin de comprobar los argumentos jurídicos que se exponen en cada caso.

El presente artículo pretende, sobre la base de una noción moderada de precedente judicial vinculante, que se explicitará, proceder a analizar si los criterios unificados, derivados de los recursos de unificación de jurisprudencia laboral acogidos por la Corte Suprema, han operado, o se han constituido, como

Lanata (2008), pp. 242-243 y en Lanata (2011), pp. 260-262. Por su parte Delgado (2011), pp. 473-494, tangencialmente refiere que la discusión sobre el valor que adquiere la jurisprudencia, a partir de la existencia del recurso de unificación, podría ser apasionada, para luego encauzar su análisis a los aspectos meramente procesales de este remedio procesal.

10 Sentencia de la Corte Suprema (en lo sucesivo SCS) en la causa rol 2886-2009, de 14 de julio de 2009.

11 Romero (2011), pp. 339-348. Este trabajo se vincula claramente con otro de mayor aliento del mismo ROMERo (2004), en el que es posible rastrear los fundamentos para las afirmaciones que se efectúan luego en el artículo de 2011.

12 ROMERO (2013), pp. 26-31.

13 Delgado y DíAz (2011), pp. 287-291.

${ }^{14}$ En este sentido HALPERN y HuMERES (2010), pp. 353, 345-374 (2010); YÁÑEZ (2010), pp. 131 151; BECERRA (2013), pp. 111-130. 
precedentes judiciales vinculantes. Nuestro trabajo abarca el periodo que va de marzo de 2008, época de inicio de entrada en vigencia de la reforma procesal laboral, y el mes de agosto de 2013, fecha en que cerramos la recopilación de los fallos que son sustento de la investigación y de sus conclusiones.

Se indica que Zhou Enlai, durante la visita de Nixon a China en 1972, y preguntado acerca de la importancia de los hechos de mayo del 68 en Francia, indicó "Es demasiado temprano para saber", ${ }^{15}$ afirmación plenamente aplicable a lo que se pueda decir ahora sobre el impacto que, en el comportamiento de la cultura judicial laboral chilena, ha de tener recurso de unificación de jurisprudencia laboral, transcurridos poco más de cuatro años desde el primer fallo que acoge uno de estos recursos. Sin embargo creemos que el ejercicio que nos proponemos puede mostrar resultados de interés, abrir debate sobre la evolución de nuestro sistema jurídico e indicar líneas de investigación jurídica que abordar en lo futuro.

\section{Marco conceptual}

\section{a) Generalidades}

Es ya un lugar común indicar que la doctrina del precedente judicial (stare decisis et non quieta movere o simplemente stare decisis) es una creación cultural que constituye e identifica al Common Law. ${ }^{16}$ Se ha hecho, también, lugar común indicar que actualmente es posible reconocer la presencia de dicho concepto en sistemas del denominado "Civil Law" o derecho continental. Indica Taruffo en este sentido que "Diversas investigaciones desarrolladas en distintos sistemas jurídicos han demostrado que la referencia al precedente, desde hace varios años, no es una característica peculiar de los ordenamientos de common law, pues está actualmente presente en casi todos los sistemas, lo que incluye al civil law. Es decir, la distinción tradicional segín la cual los primeros sistemas serian fundados sobre el precedente, mientras los segundos sobre la ley escrita no tiene en la actualidad -admitiendo que verdaderamente la baya tenido en un pasado- algún valor descriptivo". ${ }^{17}$

Se reconoce que el precedente judicial, en tanto tiende a la decisión de situaciones iguales de la misma manera, genera efectos virtuosos en los sistemas en que opera. Se afirma que si los tribunales resuelven de similar forma los casos similares, ello da seguridad jurídica (entendida como predictibilidad de las decisiones futuras), ${ }^{18}$ garantiza la igualdad de trato a los justiciables y permite ahorros en los costes de litigio. ${ }^{19}$

15 Se ha mitificado que Zhou Enlai, en la frase que citamos, se refiere a la Revolución francesa, que se desarrolla a partir de 1789 .

16 En este sentido CuETO (1997), pp. 89 y ss; SÉROUSSI (1998), pp. 27-29, 91-92; DAVID y JAufFret-Spinosi (2010), pp. 207, 212-230, 265-270; AJANI, ANDERSON, Arrollo y PASA (2010), pp. 107 y ss.

17 TARUFFO (2007), pp.85-99.

18 Indica MERRYMAN (2012), pp. 96-97, que el ideal de certeza en la tradición del derecho civil manifiesta su desconfianza en los jueces, por lo que se les prohíbe elaborar derecho, por contraste 
Soto - ¿Criterios unificados como precedentes judiciales en materia laboral?...

\section{b) Noción de precedente}

Así como la doctrina del stare decisis no tiene, en el Common Law, una única manera de entenderse; ${ }^{20}$ tampoco en la literatura que hemos consultado existe un concepto inequívoco de precedente. A fin de poder realizar nuestra investigación debemos, entonces, explicitar la noción de precedente que ocuparemos, para que se entienda claramente a que apuntamos.

Las nociones más básicas concuerdan en que los precedentes judiciales son criterios de decisión que han resuelto casos en el pasado y que son ejemplo para decidir casos similares en el futuro. Aquí se identifica al precedente como mero antecedente. ${ }^{21}$

Pero dicha forma de entender el precedente en nada ayuda a los propósitos de este trabajo. Como bien señala Victoria Iturralde en sentido propio "...un precedente solo es aquel que tiene eficacia jurídicamente vinculante para las decisiones sucesivas para casos análogos, y desde este punto de vista opera de modo semejante a una norma de origen parlamentario o gubernamental...." ${ }^{22} \mathrm{Y}$ agrega la autora, citando a su vez a Taruffo, que existe una escala de vinculatoriedad diferenciada, que permite distinguir distintos tipos de precedentes. De este modo:

1) Si la vinculación es fuerte o absoluta y sin excepciones, se habla de precedente absolutamente obligatorio;

2) Si la vinculación es fuerte pero sujeta a excepciones y limitaciones determinadas por el propio ordenamiento se habla de precedente condicionalmente obligatorio;

3) Si la vinculación es fuerte con la posibilidad de apartarse del mismo cuando el juez tenga razones relevantes para hacerlo se habla, también, de precedente condicionalmente obligatorio;

en la tradición del derecho común la certeza se logra otorgando fuerza de ley a las decisiones judiciales así "La acumulación de decisiones judiciales a través del tiempo, en una jurisdicción, provee una variedad de ejemplos concretos, detallados, de las reglas legales en operación. Estas decisiones, aunadas a las indicaciones de las propias reglas, tienden a aportar mayor certeza acerca del derecho que las meras indicaciones legislativas de las reglas...". Merryman expresa que el deseo de certidumbre es un argumento en favor del stare decisis en la tradición del derecho común, mientras que en la tradición del derecho civil es un argumento en contra del stare decisis.

${ }^{19}$ Vid. POSNER (1998), p. 508.

20 Así Cueto (1997); Ajani, Anderson, Arrollo y Pasa (1992), p. 231 -233; y, Dworkin (1992), p. 31.

${ }^{21}$ Una definición en tal sentido la da LARENZ (2001), p. 429, cuando indica que 'Los 'precedentes' son resoluciones en las que la misma cuestión jurídica sobre la que hay que resolver nuevamente, ha sido ya resuelta una vez por un tribunal en otro caso". Similar conceptualización la da la Real Academia Española: Diccionario de la Lengua Española, 22 ${ }^{a}$ Edición, 2001, p. 1233 en la segunda acepción del término precedente cuando indica que es una "acción o circunstancia anterior que sirve para juzgar hechos posteriores". En igual sentido DUXBURY (2008), p. 1, indica "A precedent is a past event - in law the event is nearly always a decision - which serves as a guide for present action..."

${ }^{22}$ ITURRALDE (2013), p. 195. 
4) Si la vinculación es débil, pero lo normal es que se siga el precedente sin que haya obligatoriedad de hacerlo y el juez no tiene que justificar el apartamiento del mismo, se habla de precedente persuasivo;

5) Si no hay vinculación y por tanto tiene el juez plena discrecionalidad de seguir o no el criterio de decisión pasado, no se está ante precedente.

Para efectos del presente trabajo utilizaremos el tipo de precedente vinculante referido en el número 3), el que denominamos para efectos de este trabajo precedente judicial vinculante moderado, porque es la forma menos exigente de precedente obligatorio en esta tipología, y supone que el tribunal a lo menos, cuando se aparte del precedente, justifique su disenso con aquel. ${ }^{23}$

\section{c) Otras clases o tipo de precedentes ${ }^{24}$}

La taxonomía de los precedentes reconoce, a partir de otros criterios distinción, la existencia de otros tipos de precedentes, a saber:

a. En cuanto a su función se distingue entre precedentes originales y precedentes interpretativos o declaratorios. Se entiende por precedente original el que crea y aplica una nueva regla de derecho o modifica un precedente anterior. Por su parte, precedente declaratorio o interpretativo es aquel que especifica una interpretación de una regla legal existente.

b. En función del sujeto que resulta vinculado se habla de precedente vertical, horizontal y auto precedentes. El precedente vertical connota que el inferior, en una estructura judicial jerárquica, está vinculado a seguir las resoluciones de su superior. El precedente horizontal describe la situación en que un tribunal está vinculado a seguir las resoluciones de sus pares. Y el auto precedente apunta a la vinculación de seguir las propias resoluciones.

Atendida la estructura del recurso de unificación, la actividad de la Corte Suprema básicamente produciría precedentes declarativos que vincularían a los inferiores (Cortes de Apelaciones y juzgados de grado) y a sí misma.

\footnotetext{
${ }^{23}$ En relación con el apartamiento o desalineamiento con el precedente, es interesante mencionar la existencia de técnicas o reglas de distinguishing y de overruling. El distinguishing permite apartarse de un precedente cuando existen diferencias fácticas, procedimentales o legales significativas entre el caso en enjuiciado y los anteriores. El overruling es el acto mediante el cual se priva de manera definitiva y formal de autoridad a un precedente. Véase AJANI, ANDERSON, ARrollo y PASA (2004), p.231; GARNER, (2004), pp. 507 y 1136-1137.

${ }^{24}$ ITURRALDE (2013), p. 196; Ríos, (2013), pp. 73-88.; NiNO (1995), p. 293; GARNER (2004), pp. $1214-1215$.
} 
Soto - ¿Criterios unificados como precedentes judiciales en materia laboral?...

\section{d) Precedente y sistema jurídico chileno}

Sin perjuicio que el presente trabajo busca verificar si los criterios unificados han operado al modo de precedentes vinculantes, de la clase que hemos elegido, y no tiene la pretensión de demostrar, argumentativamente, que en el derecho chileno las sentencias judiciales sí crean tal clase de reglas, debemos hacernos cargo, a lo menos, a si existe impedimento normativo para que ello ocurra.

La norma del inciso 2 del artículo 3 del Código Civil, que indica que "Las sentencias judiciales no tienen fuerza obligatoria sino respecto de las causas en que actualmente se pronunciaren", pareciera que se cierra la posibilidad al surgimiento del precedente vinculante. ${ }^{25}$ La disposición citada sería una consecuencia que deriva del hecho que el sistema jurídico chileno, en la tradición que se enmarca, rechazaría que los jueces sean los creadores de derecho; así ha sido leída en general por nuestra doctrina. ${ }^{26}$ Sin embargo, la lectura que hoy se hace de la mencionada norma, por algunos autores, indica que la restricción alude solo a la cosa juzgada que emana de las sentencias judiciales y que no importa restarle a la sentencia fuerza para casos futuros ${ }^{27}$ de lo que se deduce que, en dicha línea de reflexión, el sistema jurídico no está cerrado a la operación de precedentes judiciales.

Una segunda norma, la del artículo 483-C del Código del Trabajo, que expresa, específicamente en relación con el recurso de unificación, que "El fallo que se pronuncie sobre el recurso sólo tendrá efecto respecto de la causa respectiva, y en ningún caso afectará a las situaciones jurídicas fijadas en las sentencias que sirven de antecedente", daría fuerza a la doctrina que afirma el efecto relativo de las sentencias judiciales. Una simple lectura del artículo en cuestión deja claro que aquel, simplemente, se refiere a la intangibilidad de los casos regidos por las sentencias que sirven de sustento a la presentación del recurso. Dicho de otro modo, la norma del código del trabajo únicamente indica que la sentencia que crea el criterio unificado no altera el pasado, pero nada dice del futuro.

Podemos encontrar, por último, una justificación normativa a que los inferiores a la Corte Suprema deban seguir sus criterios unificados. Ello sobre la base del cumplimiento de los deberes que emanan de la Constitución y de los tratados internacionales que aseguran o garantizan la igualdad de trato por parte de los órganos del Estado. Aquella cuestión es de más largo aliento explicar y este

\footnotetext{
${ }^{25}$ Dan cuenta de ello Delgado y Díaz (2011), pp. 285-287.

${ }^{26}$ Ya se indicó que MerRYMAn (2012), p. 97, expresa que en razón de la certeza jurídica, en la tradición del derecho civil, se rechaza al stare decisis. Por lo anterior lo que dice López (2006), p.3, respecto del derecho colombiano resulta muy ajustado a lo que ha sido el análisis tradicional del derecho chileno "El sistema jurídico colombiano, neo-romanista y positivista por filiación, ha asumido tradicionalmente que (i) los jueces meramente aplican la ley, sin crearla, (ii) que los pronunciamientos judiciales son importantes para ilustrar las normas positivas sólo cuando éstas son oscuras o ambiguas, (iii) que la obligación judicial de fallar conforme a derecho se cumple preferente o exclusivamente mediante la obediencia a las reglas establecidas por el constituyente o el legislador, y (iv), como corolario de lo anterior, que los jueces están 'atados' a la ley pero que son 'independientes' frente a las sentencias judiciales con las que se han fallado casos anteriores".

${ }^{27}$ En este sentido ROMERo (2004), p.112; Ríos (2013), pp. 81-84.
} 
trabajo se satisface asumiendo que no existe restricción legal para que, como una práctica cultural del sistema, se opere con los criterios unificados al modo de precedentes vinculantes moderados. ${ }^{28}$

\section{e) El recurso de unificación de jurisprudencia laboral y el precedente}

Un par de cuestiones antes de entrar a lo que es la materia esencial del presente trabajo.

Como indicamos previamente, el modelo inicial de la reforma laboral no contemplaba, en pos de celeridad, la intervención de la Corte Suprema. La historia de la Ley 20.260 indica que la iniciativa presidencial que buscó mejorar los procedimientos laborales antes de la entrada en vigencia de la reforma, no tenía respecto del papel de la Corte Suprema un objetivo especial que lo cambiara. ${ }^{29} \mathrm{Se}$ altera el rumbo en el primer trámite constitucional; así se desprende del primer informe de la Comisión de Constitución, Legislación y Justicia, de la Cámara de Diputados, en el que se recomienda aprobar un texto que otorga a la Corte Suprema la competencia para conocer de los recursos de apelación cuando el objeto del mismo sea revisar "...la sentencia de primera instancia, en razón de haber sido dictada con infracción de garantías constitucionales o de tratados internacionales ratificados por Chile que se encuentren vigentes..." ${ }^{30}$ La posterior discusión que se genera sobre el recurso de apelación y su sustitución por un recurso de nulidad lleva a repensar nuevamente la intervención que la Corte Suprema tendrá en el nuevo proceso laboral, atendida la fisonomía claramente casacional del recurso de nulidad. Así finalmente se crea el recurso de unificación de jurisprudencia y se le asigna a la Corte Suprema esencialmente el papel de dirimir cual es el criterio de decisión más adecuado, cuando hay dispersión de los criterios de decisión, sobre una misma materia, y en fallos de tribunales superiores de justicia. ${ }^{31}$

Queremos simplemente dejar asentado que de la historia de la ley no se desprende que la función asignada a la Corte Suprema, mediante la unificación, haya sido la creación de precedentes judiciales vinculantes.

\footnotetext{
28 A quienes nos toca litigar en materia laboral podemos advertir la existencia de prácticas culturales judiciales, aun en contra de texto expreso. Un ejemplo de ello es el relativo al sentido y alcance que se da a la norma del artículo 454 número 6 del Código del Trabajo, el que prohíbe a las partes formular a los testigos preguntas en forma asertiva, ni contener ellas elementos de juicio que determinen la respuesta, sin distinguir entre el examen directo y el contraexamen. La práctica cultural de los jueces del trabajo, sobre dicha disposición, restringe la prohibición al solo examen directo, lo que es lo correcto en un sistema adversarial.

${ }^{29}$ Véase BiblioteCA DEL CONGRESO NACIONAL (2008), pp.4-15.

${ }^{30}$ BiblioteCA DEL CONGRESO NACIONAL, ibíd., p.70.

31 Sin perjuicio de consultar el texto de la evolución del recurso en BIBLIOTECA DEL CONGRESO NACIONAl (2008) dan cuenta de aquella, y de manera bastante ilustrativa, LANATA (2011), pp. 259262; y, DELGADO (2011), pp. 474-480.
} 
Soto - ¿Criterios unificados como precedentes judiciales en materia laboral?...

Las características básicas del recurso: ${ }^{32}$

a. Es un recurso extraordinario;

b. Procede contra resoluciones que fallan el recurso de nulidad;

c. La causal que sustenta el recurso es la existencia de interpretaciones distintas sostenidas en uno o más fallos firmes emanados de tribunales superiores de justicia;

d. Su plazo de interposición es de 15 días desde la dictación de la resolución que produce el agravio.

e. Se presenta ante la misma Corte de Apelaciones que dictó el fallo que se recurre y para ser conocido por la Corte Suprema.

\section{Investigación de la jurisprudencia}

\section{a) Hipótesis de trabajo}

Trabajando sobre la base del que hemos denominado precedente judicial vinculante moderado, como tipo identificatorio, nuestra hipótesis de investigación fue que se podría afirmar que los criterios unificados por la Corte Suprema operan como precedente en nuestro sistema de enjuiciamiento laboral, si se cumplen a lo menos las siguientes condiciones:

a. Que, en la dimensión de precedente vertical:

i. Se verifica alineamiento de los tribunales del trabajo y cortes de apelaciones con el criterio unificado establecido por la Corte Suprema, eso es fallan conforme a criterio unificado; o,

ii. En caso de desalineamiento, esto es fallar contra criterio unificado, los tribunales del trabajo y las cortes de apelaciones se hacen cargo, en sus respectivos fallos y de manera explícita, del criterio unificado y de las razones por las cuales en el caso particular no lo siguen.

b. Que, en la dimensión de auto precedente:

i. La Corte Suprema falla casos similares respetando su criterio unificado; o,

ii. En caso de cambiar el criterio unificado, la Corte Suprema se hace cargo de expresar, en el fallo que asienta el nuevo criterio unificado, las razones para modificar el antiguo.

\footnotetext{
32 Véase Lanata (2011), pp. 262-266; Silva (2009), p. 56; y, Delgado (2011), pp. 481-483.
} 


\section{b) Metodología}

A fin de poner a prueba la tesis, se buscó encontrar un conjunto de casos que pudiesen desacreditar a lo menos las condiciones "a.ii.", "b.i." y "b.ii", señaladas en el apartado anterior, puesto que en esa situación se puede afirmar que no hay evidencia de precedente en materia laboral. ${ }^{33}$

Para lo anterior:

a. Se revisó el universo de recursos de unificación presentados ante la Excma. Corte Suprema desde agosto de 2008 a agosto de 2013. ${ }^{34}$

b. Se escogió como muestra, para efectos de la investigación, los recursos de unificación que fueron acogidos por la Excma. Corte Suprema, en el periodo mencionado ${ }^{35}$ La elección deriva de una cuestión evidente, pues es en esos fallos el alto tribunal expresamente reconoce que existe disparidad de criterios interpretativos y luego, después de acoger el recurso, procede de manera explícita o implícita a fijar el criterio que estima correcto (criterio unificado).

c. Se analizó el conjunto de fallos y se les tabuló bajo las variables de materia de derecho objeto de la unificación y criterio unificado resultante del fallo. En general cada fallo de unificación se pronuncia sobre una materia, sin embargo excepcionalmente se pronuncia sobre dos materias distintas a la vez, lo que sucede en dos casos que encontramos.

\footnotetext{
${ }^{33}$ Limitaciones de tiempo impiden trabajar en la comprobación o desacreditación real del supuesto “a.i.", pues ello supondría encontrar dentro del universo de casos similares, a los que les sería aplicable un criterio unificado y del que no hay reiteración de unificación, una muestra de fallos que, desalineándose del criterio unificado, no den cuenta de la razón de no seguir a la Corte Suprema.

${ }^{34}$ El punto de partida de la búsqueda de los fallos está fijado a partir del trabajo de HaLIM (2010), pp. 129-134. El autor citado revisó el periodo de marzo de 2008 hasta el 8 de julio de 2010 y su cuadro resumen de recursos, en las páginas citadas, da cuenta que el primer recurso sobre el que hay algún pronunciamiento, es el rol 4793-2008, Muñoz. Hernández con Farías Ballesteros, en agosto de 2008. Dicho pronunciamiento fue la declaración de inadmisibilidad del recurso atendido a que en el juicio en el que se deduce el recurso, por tratarse de un procedimiento monitorio, no procede el recurso de unificación por disponerlo expresamente así el 502 del Código del Trabajo.

${ }^{35}$ Dicho conjunto está formado por 183 fallos: El primero corresponde a la SCS Ampuero Sánchezy otros con Agencia Maritima Alphamar S. A y Empresa Nacional del Petróleo, rol 2886-2009, de fecha 14 de julio de 2009 y el último a la SCS Gahona Avalos con Sucesión Walter Uriarte Urrutia, rol 1430-2013, de fecha 28 de agosto de 2013. Del estudio de los recursos de unificación que existen casos en que la Corte Suprema procede a una suerte de unificación impropia, pues reconociendo la disparidad de criterios se niega a unificar en el entendido que el fallo, que viene recurrido, se ajusta a la interpretación que la Corte Suprema estima adecuada.
} 
Soto - ¿Criterios unificados como precedentes judiciales en materia laboral?...

d. Se identificó el conjunto de criterios unificados a la presente fecha, se verificó el número de veces que el criterio fue reiterado y/o si el criterio fue cambiado por la Corte Suprema.

e. Para efectos de analizar si el criterio unificado opera en la dimensión de precedente vertical y revisar la condición "a.ii. En caso de desalineamiento, esto es fallar contra criterio unificado, los tribunales del trabajo y las cortes de apelaciones se hacen cargo, en sus respectivos fallos y de manera explícita, del criterio unificado y de las razones por las cuales en el caso particular no lo siguen" se estableció:

- Elegir dos criterios unificados y en que existiese reiteración de fallos de unificación. Lo anterior se hizo en atención a que en este grupo de fallos reiterados se evidencia desalineamiento, por parte de los tribunales inferiores, al criterio unificado.

- Explorar los casos de unificación reiterados, recopilando respecto de cada uno de ellos: las sentencias de instancia dictadas por los Juzgados de Letras del Trabajo y los fallos de Corte de Apelaciones recaídos sobre recurso de nulidad deducidos en cada caso, a fin de confirmar si en aquellas resoluciones el o los sentenciadores se hacen cargo de explicitar la existencia del criterio unificado y de declarar las razones por las cuales no lo siguen.

- Constituir un plazo a partir del cual se llega a conocer por los operadores jurídicos la existencia del criterio unificado y aquellos puedan, en consecuencia, tomar posición respecto del mismo. El plazo que fijamos, arbitrariamente, fue de un año a contar de la dictación del primer fallo en que se unifica una materia. Consecuencia de aquello no consideramos ninguna sentencia de Juzgado del Trabajo o de Corte de Apelaciones que hubiese sido dictada antes de ese periodo.

f. Para efectos de analizar si el criterio unificado opera en la dimensión de auto precedente y especialmente el cumplimiento de la condición b.ii. del apartado 3.1.- esto es "En caso de variar, la Corte Suprema del criterio unificado, la corte se hace cargo de expresar las razones en el fallo en que altera el criterio las razones para modificarlo", se buscaron aquellos casos en que la Corte Suprema pronunciándose sobre unificación sobre una materia es, a lo menos aparentemente, contradictoria con sus criterios unificados. ${ }^{36}$

\footnotetext{
36 Por ello no se incluyó en el análisis la anomalía consistente en que la Corte Suprema fallando recursos de casación en causas provenientes del sistema procesal antiguo, se resuelven con posterioridad a la unificación de criterio y fallando contra este. El caso ejemplar de esta situación
} 


\section{c) Recopilación de la jurisprudencia}

Como no existe una recopilación oficial de fallos de unificación, defecto que ha sido indicado como relevante para el buen funcionamiento de un sistema de precedentes, ${ }^{37}$ debimos realizar nuestra propia recolección. La tarea antes indicada no ha sido fácil y no tenemos la certeza absoluta que los 183 fallos reunidos sean el total de recursos de unificación acogidos, aunque para efectos del trabajo son suficientes. La compilación de fallos se realizó de la siguiente manera:

a. Primeramente se recurrió al sitio web del poder judicial y en la sección "Fallos C. Suprema" en "Autoconsultas" se revisaron día por día los fallos dictados por la corte. Dicho servicio del Poder Judicial permite acceder, a la fecha de realización de la investigación desde los meses de enero de 2011 a agosto de 2013. Mediante esta tarea se encontraron 116 fallos.

Sin perjuicio que aparentemente los fallos de los años 2011 a 2013 se encontraban disponibles en el web del poder judicial en la sección antes aludida, se hizo una revisión paralela de fallos del periodo en otras fuentes (Gaceta Jurídica y la base de datos de Microjuris) y se pudo comprobar que "Fallos C. Suprema" no registra actividad para los días 1 de agosto de 2012 y 2 de enero de 2013, a pesar de que en dichos días efectivamente hubo actividad de la Corte Suprema y se acogió, a lo menos un recurso de unificación en cada uno de esos días, ${ }^{38-39}$ según se descubrió del análisis de las fuentes alternativas señaladas, lo que luego se comprobó al revisar los roles y las fechas de fallo correspondientes en la sección "Corte Suprema" del mismo sitio, que es diferente a la citada "Fallos C. Suprema".

b. Enseguida, para los fallos de los años 2009 y 2010 se utilizó la recopilación hecha por Fernando Halim Muñoz, quien compila 32 fallos. El trabajo del señor Halim llega hasta inicio de junio de 2010.

c. Para el periodo que va de junio a diciembre del año 2010 se revisaron los números correspondientes a los citados meses en la Revista Gaceta Jurídica y la base de datos aludida. La revisión de Gaceta Jurídica nos entregó dos fallos y Microjuris seis sentencias.

\footnotetext{
es la SCS rol 7209-2011, fallada el 9 de marzo de 2012, y en que la sala de verano de la Corte Suprema establece que en el concepto de ultima remuneración se deben considerar las asignaciones de colación y remuneración si se pagan mes a mes, criterio diferente al que ha sostenido consistentemente desde abril de 2010 la sala cuarta de la Corte Suprema.

37 Delgado (2011), p. 483; AjAni, Anderson, Arrollo y PASA (2010), p. 232 aluden a la importancia que adquiere en el derecho norteamericano la facilidad para localizar los datos jurisprudenciales, que facilita la circulación y conocimiento de las sentencias más relevantes.

38 SCS rol 9669-2011, 1 de agosto de 2012.

${ }^{39}$ SCS 4291-2012, 2 de enero de 2013.

${ }^{40}$ La situación sigue siendo la misma al 6 de septiembre de 2013, última revisión del web del poder judicial.
} 
Soto - ¿Criterios unificados como precedentes judiciales en materia laboral?...

Sin embargo ellos no son los únicos recursos de unificación acogidos en el periodo, pues la revisión del trabajo de Jordi Delgado e Iván Díaz, ${ }^{41}$ nos proporcionó cinco más. Por último un trabajo de Romero Seguel nos mostró una sentencia del periodo aludido. ${ }^{42}$

\section{d) Criterios unificados}

Revisados los 183 fallos a que hemos hecho referencia podemos indicar que se han unificado los siguientes criterios:

1) Con relación a contratos de plazo indefinido: La Corte Suprema estableció que es improcedente la aplicación de causal de conclusión del trabajo o servicio que dio origen al contrato, contemplada en el artículo 159 número 5 del Código del Trabajo, a los contratos de trabajo pactados por tiempo indefinido. ${ }^{43}$

2) Con relación al valor de los finiquitos laborales: La Corte Suprema fijó el criterio en orden a que el finiquito válidamente otorgado, que cumple las formalidades del artículo 177 del Código del Trabajo, y respecto del cual no ha habido reserva alguna, tiene pleno efecto liberatorio. ${ }^{44}$

3) Con relación al estatuto aplicable a particulares que celebran contratos de honorarios con una municipalidad: La Corte Suprema estableció que los contratos de prestación de servicios a honorarios, celebrados entre un particular y una Municipalidad, se regulan por las normas contenidas en el propio contrato de honorarios, conforme se establece en el artículo $4^{\circ}$ de la Ley $\mathrm{N}^{\circ} 18.883$, sin que le sean aplicables dicho Estatuto, ni las disposiciones del Código del Trabajo. ${ }^{45}$ Sobre este particular hay dos pronunciamientos en similar sentido en los años 2009 y 2013.

4) Con relación a la sanción de ineficacia de despido, por existir deudas de cotizaciones previsionales a la época de aquel: Encontramos 29 fallos diferentes que regulan los alcances respecto de aquella sanción de ineficacia y que se traduce, de conformidad al artículo 162 del Código del Trabajo, en la obligación de pagar el empleador remuneraciones hasta que se convalide el despido por el integro de la cotizaciones previsionales adeudadas. Los aspectos unificados son los siguientes:

\footnotetext{
${ }^{41}$ DELGADO y DíAz (2011), pp. 287-290.

42 ROMERO (2013), p. 31

43 SCS, rol 2886-2009, 14 de julio de 2009.

${ }^{44}$ SCS, rol 5816-2009, 27 de octubre de 2009.

45 SCS rol 6335-2009, 10 de noviembre de 2009.
} 
a. Que priman sobre la sanción referida las normas de la ley de quiebras. De este modo una vez declarada la quiebra no se siguen devengando remuneraciones. ${ }^{46}$ Ello es así porque no es posible gravar la masa con mayores obligaciones que las que quedan fijadas a dicha fecha, límite al cual debe entonces ceñirse el deber de pago de remuneraciones y cotizaciones que se devenguen.

b. Que la sanción aludida no se puede aplicar al empleador cuando ha sido la sentencia la que ha determinado que la remuneración del trabajador era superior a la estipulada en el contrato y respecto de cuya diferencia establecida en su favor, no se han retenido ni enterado cotizaciones previsionales. ${ }^{47}$

c. Que no corresponde aplicar la sanción cuando la sentencia determina el vínculo laboral y, por lo tanto, el empleador no ha obrado como agente retenedor de las cotizaciones previsionales. ${ }^{48}$

d. Que no procede aplicar la sanción cuando la sentencia reconoce el derecho al trabajador a percibir semana corrida. ${ }^{49}$

e. Que la sanción no se aplica cuando es el trabajador quien pone término al contrato por la causal establecida en el artículo 171 del Código del Trabajo, esto es despido indirecto o autodespido. ${ }^{50}$

5) Con relación a la presunción de representación del empleador: La Corte Suprema estableció que una vez probado el hecho que determina la presunción de representación del empleador, solo cabe aplicar la norma, quedando vedado considerar cualquier circunstancia fáctica para preterir la disposición legal que libera de la obligación de probar. ${ }^{51}$

6) Con relación al artículo 87 de la Ley 19.070, Estatuto Docente, y a los artículos 161 y 168 del Código del Trabajo: La Corte Suprema fijó los alcances de la asimilación o ficción que dispone el inciso $3^{\circ}$ del aludido artículo 168 del Código del ramo para efectos del pago de la indemnización adicional contemplada por el artículo 87 de la Ley $\mathrm{N}^{\circ} 19.070$, en orden a que aquel efecto no constituye un presupuesto de aplicación de la segunda norma cuando la causal invocada por el empleador para la desvinculación no ha sido alguna de las previstas en el

\footnotetext{
${ }^{46}$ SCS rol 7076-2009, 28 de enero de 2010.

${ }^{47}$ SCS rol 9265-2009, 8 de abril de 2010.

${ }^{48}$ SCS rol 852-2010, 20 de abril de 2010.

${ }^{49}$ SCS rol 4584-2011, 15 de diciembre de 2012.

${ }^{50}$ SCS rol 6510 -2010, 24 de marzo de 2011.

${ }^{51}$ SCS rol 4595-2009, 28 de enero de 2010.
} 
Soto - ¿Criterios unificados como precedentes judiciales en materia laboral?...

artículo 161 del primer cuerpo legal citado. $^{52}$ Este tipo de pronunciamiento se repite dos veces más en el periodo estudiado.

7) Con relación al artículo 3 de la Ley 18.883, Estatuto Administrativo para los funcionarios municipales: La Corte Suprema sostiene que la aplicación del Código del Trabajo, establecida para casos determinados en el artículo 3 de la Ley 18.883, debe necesariamente tener un carácter restrictivo por cuanto, dada la naturaleza de la empleadora, la contratación de una persona en forma indefinida importa una investidura como funcionario de planta, cargo cuyos requisitos de postulación, procedimiento de nombramiento y demás aspectos están específicamente reglados en las disposiciones pertinentes de la ley referida. ${ }^{53}$

8) Con relación al concepto de última remuneración para efectos indemnizatorios: La Corte Suprema fijó el criterio que, dentro del concepto de última remuneración, que establece el artículo 172 del Código del Trabajo, no se pueden incluir los estipendios no remunerativos que se describen en el artículo 41 del mismo texto legal. ${ }^{54}$ Este pronunciamiento se repite 26 veces en el periodo objeto del estudio, siendo el último detectado en mayo de 2013.

9) Con relación a las indemnizaciones establecidas en el artículo $2^{\circ}$ transitorio de la Ley 19.070, Estatuto Docente: la Corte Suprema sostiene que la correcta aplicación del artículo $2^{\circ}$ transitorio de la Ley $\mathrm{N}^{\circ} 19.070$, es que no se tiene derecho a la indemnización por años de servicios contemplada en dicha norma, cuando la causal de cese de los servicios es la renuncia voluntaria del trabajador y no por necesidades de la empresa, siendo imposible, entonces, que ambas situaciones puedan jurídicamente homologarse. ${ }^{55}$ Sobre esta materia, en el periodo que nos ocupa, se volvió a pronunciar 28 veces más, 26 de las sentencias se dictan entre abril y diciembre de 2010, una en marzo de 2011 y la última en agosto de 2012.

10) Con relación a la causal de término de la relación laboral por conclusión del trabajo o servicio que dio origen al contrato: La Corte Suprema unificó la jurisprudencia en el sentido que resulta justificada la aplicación de la citada causal, cuando los contratos de trabajo están asociados a una faena cuya duración depende de una condición ajena a la voluntad del empleador y ellas es conocida por los trabajadores. ${ }^{56}$

\footnotetext{
52 SCS, rol 8550-2009, 17 de marzo de 2010.

53 SCS, rol 6778-2009, 25 de marzo de 2010.

54 SCS, rol 9603-2009, 21 de abril de 2010.

55 SCS, rol 9024-2009, 21 de abril de 2010.

${ }^{56}$ SCS, rol 6024-2012, 17 de enero de 2013.
} 
11) Con relación a las indemnizaciones por término de contrato y las compensatorias del fuero: La Corte Suprema fijó el criterio que son incompatibles las indemnizaciones por falta de aviso previo y por años de servicio con las indemnizaciones que compensan el fuero del trabajador, puesto que estas reparaciones constituyen sanciones pecuniarias $-y$, por tanto, resarcimientos- que emanan de un mismo hecho, en este caso la terminación de la relación laboral por decisión del empleador, en contravención a las normas que regulan la materia, pero con diferentes procedimientos y bases de cálculo. ${ }^{57}$

12) Con relación al fuero maternal y contratos de reemplazo de profesionales de la educación: La Corte Suprema, unificando la interpretación del artículo 72 de la Ley 19.070 o Estatuto Docente, con relación a los artículos 174 y 201 del Código del Trabajo, fijó el criterio que en el caso de las profesionales de la educación que estén vinculados en virtud de un contrato de reemplazo y que a la fecha de término de sus servicios se encuentren embarazadas, no resulta procedente exigir al empleador solicitar su desafuero. ${ }^{58}$

13) Con relación a las causales de término de contrato de trabajo de falta de probidad y conducta inmoral, establecidas en el artículo 72 letra b) de la Ley 19.070 del estatuto docente: La Corte Suprema unificó en el sentido que respecto de un docente del sector municipal que es despedido por alguna de las causales establecidas en la letra b) del artículo 72 de la Ley 19.070, esto es probidad y conducta inmoral establecidas fehacientemente en un sumario, no se aplican las formalidades del despido establecidas en el artículo 162 del Código del Trabajo. ${ }^{59}$

14) Con relación a pensiones de montepío de la Caja de Retiro y de Previsión Social de los Ferrocarriles del Estado: La Corte Suprema estableció, con relación al derecho a acrecer contenido en el artículo $3^{\circ}$ letra c) de la Ley $\mathrm{N}^{\circ} 12.522$, que este resulta improcedente en el caso que fallezca la viuda del causante después de haberse deferido y le sobrevivan hijos con derecho ya reconocido a pensión de montepío. ${ }^{60}$

15) Con relación a la prestación de semana corrida: La Corte Suprema fijó el criterio que los trabajadores incorporados en la parte final del inciso primero del artículo 45 del Código del Trabajo, afectos a un sistema remuneracional mixto, integrado por sueldo mensual y remuneraciones variables, solo tienen derecho al pago de la semana corrida, en la medida que sus remuneraciones variables sean devengadas día a día, y en cambio

${ }^{57}$ SCS, rol 3903-2013, 7 de octubre de 2010.

${ }^{58}$ SCS, rol 2821-2010, 19 de octubre de 2010.

${ }^{59}$ SCS, rol 5831-2010, 26 de noviembre de 2010.

${ }^{60}$ SCS, rol 6246-2010, 25 de enero de 2011. 
Soto - ¿Criterios unificados como precedentes judiciales en materia laboral?...

no lo tienen, si tales remuneraciones se devengan en una unidad de tiempo distinta. ${ }^{61}$ Este criterio se repite en diecinueve fallos más dictados entre enero de 2011 y abril de 2013.

16) Con relación a prescripción de remuneraciones: La Corte Suprema estableció que tratándose del cobro de remuneraciones de un trabajador cuyo contrato de trabajo ha finalizado, el plazo de prescripción aplicable es el previsto en el inciso segundo del artículo 510 del Código del Trabajo, esto es, de seis meses contados desde el cese de los servicios. ${ }^{62}$

17) Con relación al límite de última remuneración: La Corte Suprema estableció que la circunstancia que la remuneración efectivamente percibida por el trabajador haya sido superior a 90 unidades de fomento, no le resta certeza al alcance del precepto aludido, como tampoco importa una excusa para soslayar su aplicación, por cuanto las normas que regulan la materia son de orden público y constituyen un imperativo para el tribunal cuando no existe pacto expreso de las partes dirigido a mejorar las condiciones económicas del dependiente exonerado, por la vía de fijar compensaciones superiores o ajenas a las restricciones legales. ${ }^{63}$

18) Con relación a la aplicación de sanción de ineficacia de despido o ley Bustos en contra de la empresa principal: La Corte Suprema inicialmente estimó que la empresa mandante es solidariamente responsable con el empleador del trabajador, respecto del pago de remuneraciones por ineficacia de despido. ${ }^{64}$ Sin embargo el criterio fue cambiado con posterioridad en el sentido que no corresponde aplicar la sanción al mandante de la obra, puesto que, en tanto sanción, es de derecho estricto y, por ende, de interpretación y aplicación restrictiva. ${ }^{65}$

19) Con relación a la competencia de los tribunales laborales para conocer de vulneraciones de garantías de funcionarios públicos: $\mathrm{La}$ Corte Suprema sienta criterio en el sentido que los juzgados laborales son incompetentes absolutamente, en razón de la materia, para conocer de una demanda de tutela de derechos laborales fundamentales incoada por funcionarios públicos designados en calidad de contratas en una Intendencia Regional en sus respectivos cargos. ${ }^{66}$ En octubre de 2010 el criterio se reitera respecto de una funcionaria a contrata en una Gobernación Provincial.

\footnotetext{
${ }^{61}$ SCS, rol 6552-2010, 27 de enero de 2011.

62 SCS, rol 7104-2010, 24 de marzo de 2011.

${ }^{63}$ SCS, rol 6300-2010, 25 de marzo de 2011.

${ }^{64}$ SCS, rol 7502 - 2010, 31 de marzo de 2011.

${ }^{65}$ SCS, rol 9669 - 2011, 1 de agosto de 2012.

${ }^{66}$ SCS, rol 1972-2011, 5 de octubre de 2011.
} 
20) Con relación al fuero de constitución de sindicatos: La Corte Suprema fija el criterio que el fuero de constitución de un sindicato le es inoponible al empleador cuando no ha mediado la comunicación a que alude el artículo 221 del Código del Trabajo, por lo que no corresponde restarle validez a un despido cuando el fuero ha sido desconocido para el empleador. $^{67}$

21) Con relación a la aplicabilidad de las normas de despido a los trabajadores de la salud municipal: La Corte Suprema unifica la jurisprudencia en el sentido que respecto de la terminación de los servicios de una matrona que prestaba servicios en el área de salud formando parte de la dotación de una Corporación Municipal, trabajadora que anteriormente laboraba en el mismo rubro para la Municipalidad respectiva, no le son aplicables las normas del Código del Trabajo, sino que la Ley $\mathrm{N}^{\circ} 19.378 .{ }^{68}$

22) Con relación al concepto de caso fortuito o fuerza mayor como causal de terminación del contrato de trabajo: La Corte Suprema estableció que la irresistibilidad, para los efectos de la causal de cese de servicios invocada, importa la inexistencia de posibilidad de mantener el puesto de trabajo de los dependientes y, por ende, de cumplir una de las principales obligaciones contractuales de la parte empleadora, tornándose inviable la mantención del vínculo e inevitable el término del mismo. La exigencia de prueba al efecto por parte del tribunal resulta esencial; en tanto, la mencionada precedentemente corresponde a una de las tres características que el legislador impone al hecho cuya verificación fuerza el despido. ${ }^{69}$

23) Con relación a la indemnización establecida en el artículo 73 del Estatuto Docente: La Corte Suprema dejó asentado que se tiene derecho además del pago de las diferencias de la indemnización por años de servicios al pago de las remuneraciones desde la fecha de la separación hasta que no se haga solución íntegra y total de la referida indemnización. ${ }^{70}$

24) Con relación a la normativa aplicable a los profesionales contratados sobre la base de honorarios por la administración del Estado: La Corte Suprema fijó que a los profesionales contratados a través de contratos de prestación de servicios a honorarios por el Ministerio Secretaría General de Gobierno, sus relaciones se rigen por las estipulaciones contenidas en dichas convenciones y no les resultan

${ }^{67}$ SCS, rol 829-2011, 22 de diciembre de 2011.

${ }^{68}$ SCS, rol 5316-2011, 23 de marzo de 2012.

${ }^{69}$ SCS, rol 6008-2011, 11 de abril de 2012.

${ }^{70}$ SCS, rol 8788-2010, 14 de abril de 2012. 
Soto - ¿Criterios unificados como precedentes judiciales en materia laboral?...

aplicables las normas del Código del Trabajo. ${ }^{71}$ Igual criterio se sigue para personal contratado por organismos de la administración descentralizada del Estado en tres fallos dictados entre mayo de 2012 y abril de 2013.

25) Con relación a la competencia territorial para conocer de juicios contra el Instituto de Previsión Social: La Corte Suprema establece el criterio que el juez competente para conocer de las cuestiones derivadas de la aplicación de las normas de previsión planteadas por pensionados, específicamente en lo referente al cálculo del bono de reconocimiento y en las que el demandado sea el Instituto de Previsión Social, es un juez de Santiago, atendido a que el director de dicha entidad tiene ahí su domicilio. ${ }^{72}$

26) Con relación a la oferta irrevocable de indemnización contenida en la carta de despido: La Corte Suprema asentó el criterio que la oferta irrevocable de pago a que se refiere el artículo 169 letra a) del Código del Trabajo, no aceptada por el actor, no debe ser tomada en cuenta para los efectos de la determinación del monto de las indemnizaciones propias del despido. $^{73}$

27) Con relación al despido indirecto dado por profesionales de la educación regidos por el Estatuto Docente: La Corte Suprema estableció como criterio unificado que el artículo 171 del Código del Trabajo no resulta aplicable a los profesionales de la Educación regidos por el estatuto docente; que estos no tienen derecho a indemnizaciones por el término de su contrato de trabajo sino cuando expresamente el mencionado estatuto lo contemple; y que la sanción del artículo 162 inciso séptimo del Código Laboral, de haber sido aplicable este cuerpo de normas igualmente no rige cuando, como en la especie, es el trabajador quien pone término a la relación laboral, de conformidad con lo dispuesto en el artículo 171 del Código citado. ${ }^{74}$

28) Con relación al cálculo del Bono SAE: La Corte Suprema fijó el criterio que, tratándose de los profesionales de la educación municipalizados, las expresiones "incremento del valor hora en los años en que procedió" importan descontar, de los haberes a considerar para determinar la existencia del bono de excedentes, los aumentos que ha experimentado el valor hora desde el año 1998 en adelante. ${ }^{75}$ Dicho criterio se reitera en 20 fallos más dictados entre los meses de septiembre de 2012 y julio de 2013.

\footnotetext{
${ }^{71}$ SCS, rol 5839-2011, 25 de abril de 2012.

72 SCS, rol 4790-2011, 16 de mayo de 2012.

${ }^{73}$ SCS, rol 7870-2011, 20 de julio de 2012.

${ }^{74}$ SCS, rol 10266-2011, 3 de agosto de 2013.

${ }^{75}$ SCS, rol 10871-2011, 29 de agosto de 2012.
} 
29) Con relación a lucro cesante: La Corte Suprema estableció, en relación con la forma en que debe fijarse la indemnización por lucro cesante, que se requiere necesariamente de la demostración de la falta de producción del ingreso o la mantención del pasivo y la determinación del quántum de la ganancia, sin que baste para ello la sola perpetración o acaecimiento del hecho dañoso, no pudiendo determinarse o cuantificarse este rubro exclusivamente en base a un juicio de probabilidades. ${ }^{76}$

30) Con relación a la causal de incumplimiento grave de las obligaciones que impone el contrato de trabajo: La Corte Suprema estableció que el contrato de trabajo se caracteriza también por su contenido ético, es decir, por el imperio de ciertos principios que las partes deben respetar, entre ellos, el deber de fidelidad y lealtad a que ambas se encuentran obligadas. Por lo mismo, las relaciones laborales han de desenvolverse en un clima de confianza, el que se genera en la medida en que las partes cumplan con sus obligaciones en la forma estipulada, de buena fe, principio del cual se encuentra imbuida toda la legislación nacional y consagrado, especialmente en materia contractual, en el artículo 1546 del Código Civil. De esta manera, los mencionados deberes constitutivos de la carga ética aludida son claras directrices del comportamiento de los contratantes durante la vigencia de su vinculación, sujetándolos a varias obligaciones que, con independencia de su explicitación en el texto del contrato pertinente o consensuados expresamente, emanan de la naturaleza de la relación laboral y deben considerarse integrantes del mismo. ${ }^{77}$

31) Con relación al pacto de gratificaciones: La Corte Suprema fijó criterio en el sentido que si las partes pactaron el pago de gratificaciones ajustándose al mínimo legal, consistente en 4,75 Ingresos Mínimos Mensuales al año o por ejercicio comercial, es a dicho límite al que debe estarse. Precisa la Corte que dicho límite legal es anual o por ejercicio comercial, toda vez que dicho período es aquel en el cual se devenga y calcula el beneficio en análisis, como se desprende de lo dispuesto en el artículo 47 inciso primero, parte segunda, en cuanto afirma que "la gratificación de cada trabajador con derecho a ella será determinada en forma proporcional a lo devengado por cada trabajador en el respectivo período anual, incluidos los que no tengan derecho". ${ }^{78}$

32) Con relación a indemnización compensatoria de fuero y despido indirecto: La Corte Suprema fijó criterio en el sentido que resulta improcedente el pago de las remuneraciones hasta el término del fuero que ostentaba un miembro del Comité Paritario de la empresa, cuando ha

\footnotetext{
${ }^{76}$ SCS, rol 11675-2011, 16 de octubre de 2012.

77 SCS, rol 821-2012, 18 de octubre de 2012.

${ }^{78}$ SCS, rol 4399-2012, 17 de enero de 2013.
} 
Soto - ¿Criterios unificados como precedentes judiciales en materia laboral?...

sido el propio trabajador el que, mediante el ejercicio del derecho que le otorga el artículo 171 del Código del Trabajo, que le pone término a la relación laboral. ${ }^{79}$

33) Con relación a la indemnización por despido vulneratorio de garantías y despido indirecto: La Corte Suprema estableció que la acción prevista por el inciso $1^{\circ}$ del artículo 489 del Código del Trabajo no procede cuando ha sido el trabajador quien ha puesto término a la relación laboral por la vía del despido indirecto contenida en el artículo 171 del precitado cuerpo normativo. ${ }^{80}$ Este criterio se vuelve a repetir en un fallo de agosto de 2013.

34) En cuanto al contenido de la carta de despido y la recepción a prueba de la causa: La Corte Suprema indicó que el criterio que la adecuada interpretación del artículo 453 número $3^{\circ}$ del Código del Trabajo, es que resulta procedente recibir la causa a prueba en caso de existir hechos sustanciales, pertinentes y controvertidos en un procedimiento en que la materia está constituida por la calificación de la causal de despido por necesidades de la empresa, particularmente si se fundó en "una modernización o racionalización en el área" en que se desempeñaba la trabajadora. ${ }^{81}$

35) En cuanto al reemplazo de trabajadores: La Corte Suprema estableció que la adecuada e integral interpretación del artículo 381 del Código del Trabajo, importa que debe entenderse que la ley impide -salvo en las condiciones excepcionales que ella misma regula- la contratación de nuevos trabajadores para desempeñar las funciones de aquellos que han declarado la huelga, es decir, debe tratarse de personal ajeno a la empresa. ${ }^{82}$

36) Con relación a la normativa que rige a la empresa principal en accidentes del trabajo: La Corte Suprema estableció el criterio que la responsabilidad de la empresa principal en un accidente de trabajo solo puede ser declarada a virtud de un incumplimiento de las obligaciones propias y particulares que la ley le ha impuesto sobre la materia, y no como garante de las obligaciones que ha debido cumplir el empleador. ${ }^{83}$

37) Con relación a prácticas antisindicales: La Corte Suprema asentó el criterio que tratándose de las conductas que sanciona la norma del artículo

\footnotetext{
${ }^{79}$ SCS, rol 5567-2012, 18 de enero de 2013.

${ }^{80}$ SCS, rol 2202-2012, 18 de enero de 2013.

81 SCS, rol 6940-2012, 7 de marzo de 2013.

${ }^{82}$ SCS, rol 4936-2012, 7 de marzo de 2013.

${ }^{83}$ SCS, rol 5620-2012, 27 de marzo de 2013.
} 
289 del Código del Trabajo, debe concurrir la intención precisa de parte del empleador de atentar contra la libertad sindical. ${ }^{84}$

38) Con relación a reliquidación de pensiones de la Ley 15.386: La Corte Suprema estableció el criterio que no corresponde aplicar el tope o límite del artículo 25 de la Ley $\mathrm{N}^{\circ} 15.386$ frente a la petición de reliquidación de una pensión de viudez derivada de una pensión de jubilación de que gozaba el causante de la misma, cuando esta fue concedida y calculada conforme a la misma norma legal, pues lo contrario conlleva una doble e injusta restricción a la pensión de viudez. ${ }^{85}$

39) Con relación a la base de cálculo de semana corrida y la norma transitoria de la Ley 20.281: La Corte Suprema estableció como criterio unificado que la base de cálculo para determinar el beneficio de la semana corrida no puede considerar o comprender la porción o monto de aquellas remuneraciones variables que el empleador ha debido utilizar para integrar el sueldo base de los trabajadores hasta completar el ingreso mínimo mensual de la época, en la forma dispuesta por el artículo transitorio de la Ley $\mathrm{N}^{\circ} 20.281$ de $2008 .^{86}$

40) Con relación a la normativa aplicable al personal paradocente: La Corte Suprema fijó el criterio que al personal paradocente, asistente de la educación, de los establecimientos educacionales administrados directamente por las municipalidades, se les aplican las normas de los artículos 110 a 112 de la Ley $\mathrm{N}^{\circ} 18.883$, ubicados en el párrafo $4^{\circ}$ del Título IV denominado: "Derechos Funcionarios", por disposición del artículo $4^{\circ}$ de la Ley $\mathrm{N}^{\circ}$ 19.464, quedando excluido el artículo 148 del Estatuto Administrativo para Funcionarios Municipales, que está ubicado en el Título VI: "De la Cesación de Funciones". ${ }^{87}$

41) Con relación a la normativa sancionatoria que corresponde aplicar a actos, omisiones o imprudencias temerarias que se encuentran descritas en el reglamento interno: La Corte Suprema estableció que si la conducta del dependiente constituye una imprudencia temeraria inexcusable que puso en una situación de alto riesgo a otro trabajador y se encuentra ella prohibida en el reglamento interno de la empresa, no implica que solo pueda ser sancionado el infractor de la forma establecida en el artículo $154 \mathrm{~N}^{\circ} 10$ del Código del Trabajo, más si la propia normativa de la empresa contempla la posibilidad de sustraer determinadas infracciones del procedimiento sancionatorio interno,

${ }^{84}$ SCS, rol 7856-2012, 4 de abril de 2013.

${ }^{85}$ SCS, rol 6163-2012, 29 de abril de 2013.

${ }^{86}$ SCS, rol 6159-2012, 30 de abril de 2013.

${ }^{87}$ SCS, rol 9013-2012, 15 de mayo de 2013. 
Soto - ¿Criterios unificados como precedentes judiciales en materia laboral?...

cuando por su gravedad configuren alguna de las causales de caducidad del contrato de trabajo. ${ }^{88}$

42) Con relación a lucro cesante por término anticipado e injustificado de un contrato a plazo fijo: La corte Suprema estableció el criterio que tratándose del término anticipado e injustificado de un contrato a plazo fijo, el trabajador tiene derecho a reclamar la indemnización por lucro cesante, esto es, las remuneraciones que le hubiere correspondido percibir hasta el término del contrato. ${ }^{89}$

43) Con relación al incumplimiento grave de obligaciones que impone el contrato invocada por ausencia que no llegan a constituir la causal específica: La Corte Suprema sostuvo que impedir a la parte empleadora la invocación de ausencias injustificadas y reiteradas en el tiempo para fundamentar un incumplimiento grave del contrato de trabajo, importa no solo la desatención de las reglas de la sana crítica al momento de apreciar los presupuestos fácticos construidos a partir de los antecedentes, sino que también extremar el sentido y ámbito de aplicación de la institución contenida en la norma de que se trata, sobre la base de que uno de los contratantes -el empleador- acepte continuos y graves incumplimientos al deber de prestar el servicio convenido, mientras no se configure la causal específica de caducidad del contrato, lo que llevaría a permitir que un dependiente faltase sin justificación y sin sanción alguna dos días todos los meses del año, siempre y cuando estos días no sean seguidos o días lunes en el mes, cuestión que resulta contraria, a todas luces, a las obligaciones y deberes que integran la convención que une a las partes. ${ }^{90}$

44) Con relación al ajuste de sueldo base y el alcance de la norma transitoria de la Ley 20.281: La Corte Suprema estableció que el ajuste dispuesto por el artículo transitorio de la Ley $\mathrm{N}^{\circ} 20.281$ - para equiparar el sueldo base de los trabajadores que allí se menciona al ingreso mínimo vigente a la época de publicación de la ley, ello, con cargo a las remuneraciones variables de los trabajadores y para cuya implementación se otorgó un plazo de seis meses- debe continuar más allá de vencido ese lapso, con la misma modalidad, para los efectos de enterar la suma de \$159.000 que corresponde al ingreso mínimo al 21 de julio de 2008, fecha de publicación de la ley citada. ${ }^{91}$ Este criterio se reitera en un fallo de agosto de 2013.

45) Con relación a inmunidades de jurisdicción: La Corte Suprema asentó el criterio que los juzgados laborales carecen de jurisdicción para conocer

88 SCS, rol 292-2013, 25 de mayo de 2013.

${ }^{89}$ SCS, rol 8465-2012, 29 de mayo de 2013.

${ }^{90}$ SCS, rol 1242-2013, 13 de junio de 2013.

${ }^{91}$ SCS, rol 7366-2012, 20 de junio de 2013. 
de una demanda incoada por dependientes nacionales en contra de sus empleadores, cuando estos invisten la calidad de Estados extranjeros asentados en nuestro país. ${ }^{92}$

46) Con relación a intereses y reajustes aplicables a las indemnizaciones por daño moral derivado de accidente de trabajo: La Corte Suprema estableció que, conforme a lo expuesto y razonado, se unifica la jurisprudencia en el sentido que, tratándose de la indemnización por el daño moral derivado de un accidente del trabajo, los reajustes e intereses con que debe incrementarse el resarcimiento fijado -en las situaciones previstas por la letra b) del artículo 69 de la Ley $\mathrm{N}^{\circ} 16.744-$ son aquellos regulados por el derecho común y no los establecidos en los artículos 63 y 173 del Código del Trabajo.

\section{e) Casos de desalineamiento de Juzgados del Trabajo y/o Cortes de Apelaciones respecto del criterio unificado}

\section{i) Elección de criterios}

Para encontrar fallos de Tribunales del Trabajo y de Cortes de Apelaciones que se hubiesen dictado en el periodo posterior al año de dictación de la primera unificación, elegimos dos conjuntos de sentencias, que se referían a materias que presentaban una unificación temprana (esto es a los inicios de la reforma) y en las que se había producido reiteración de unificaciones hasta la época de cierre de la investigación.

Dichas materias son la sanción del artículo 162 del Código del Trabajo y la prestación de semana corrida.

ii) Casos de desalineamiento con criterio unificado relativos al artículo 162 del Código del Trabajo

El conjunto de fallos que se analiza, con relación al criterio unificado, giran sobre la discusión de si corresponde sancionar al empleador con el pago de remuneraciones hasta convalidación de despido sanción, cuando ha sido la sentencia la que ha declarado la existencia de la relación laboral. La Corte Suprema ha estimado que en dicho caso la sentencia es constitutiva y por ende no corresponde aplicar la sanción en cuestión. El primer fallo que unifica la materia lo encontramos en la causa "Núnez. Arancibia con Sociedad Contractual Minera Tambillos", rol 852-2010 de fecha 24 de abril de 2010.

Los fallos contrastados a este criterio son todos aquellos que fueron dictados por Juzgado del Trabajo y/o por Cortes de Apelaciones con

\footnotetext{
${ }^{92}$ SCS, rol 1224-2013, 13 de agosto de 2013.
} 
Soto - ¿Criterios unificados como precedentes judiciales en materia laboral?...

posterioridad al 24 de abril de 2011 y que dieron lugar a una nueva unificación en la misma materia. Ellos son:

a. Unificación "Orrego Siebert Con Empresa Periodística La Cuarta S.A.", rol 8989-2011, dictada el 29 de agosto de 2012 y que corresponde al RUC 114-0007546-K: Fue fallada en instancia el día 13 de julio de 2011 por el Juzgado de Letras del Trabajo de Valparaíso y por Corte de Apelaciones de Valparaíso el 19 de agosto de 2011. Ni el fallo del Juzgado del Trabajo, ni el de la Corte de Apelaciones se hacen cargo del criterio unificado, a pesar de fallar contra él.

b. Unificación "Olivares con Pontificia Universidad Católica de Chile", rol 1855-2012, dictada el 28 de noviembre de 2012 y que corresponde al RUC 11-4-0006832-3: Fue fallada por el Segundo Juzgado de Letras del Trabajo de Santiago el día 21 de abril de 2011 y por la Corte de Apelaciones de Santiago el 24 enero de 2012. Si bien el fallo del Tribunal del Trabajo queda por tres días fuera del rango que nos hemos fijado se debe mencionar que no se hace cargo del criterio unificado, a pesar de fallar contra él. En el fallo de la Corte de Apelaciones no se hace mención al criterio unificado de la Corte Suprema, a pesar de declarar la validez del fallo de instancia.

c. Unificación "Riquelme Alfaro con Pontificia Universidad Católica de Chile", rol 1681-2012, dictada el 28 de noviembre de 2012 y que corresponde al RUC 11-4-0009352-2: Fue fallada por el Segundo Juzgado del Trabajo de Santiago el día 7 de mayo de 2011, el tribunal no se hace cargo del problema jurídico que nos ocupa atendido que la demandada no contestó la demanda y por ende no se opusieron alegaciones en el orden que nos interesa. El fallo del tribunal laboral fue recurrido de nulidad y en el recurso, como fundamento, se arguye el criterio unificado que nos interesa y la Corte de Apelaciones de Santiago, el día 11 de enero de 2012, rechazó el recurso de nulidad, indicando que la interpretación del tribunal de instancia al artículo 162 del Código del Trabajo es correcto y no se hace cargo de la línea de unificación establecido por la Corte Suprema.

d. Unificación "Faúndez Olave con Comercial Abraham Pichara y Cía. Ltda.", rol 7443-2012, dictada el 21 de marzo de 2013 y que corresponde al RUC 12-4-0007179-7: La causa fue resuelta en instancia el día 22 de mayo de 2012 por el Juzgado de Letras del Trabajo de Curicó y por la Corte de Apelaciones de Talca el 27 de julio de 2012. El sistema del poder judicial no permite acceder de cierre de este trabajo a la sentencia dictada por el tribunal de instancia. Respecto de lo resuelto por la Corte de Apelaciones de Talca es perceptible que no menciona el criterio unificado y falla en contra del mismo. 
e. Unificación "Toledo Ávila con Transportes y Comercial Bercy del Carmen Oyarzun Diaz E.I.R.L.”, rol 338-2013, dictada el 2 de julio de 2013 y que corresponde al RUC 12-4-0013504-3: La causa fue conocida en instancia por el Juzgado de Letras del Trabajo de Curicó, el que la falló el día 27 de agosto de 2012 y la Corte de Apelaciones de Talca se pronunció en recurso de nulidad el 7 de noviembre de 2012. El sistema del poder judicial no permite acceder de cierre de este trabajo a la sentencia dictada por el tribunal de instancia. Respecto de lo resuelto por la Corte de Apelaciones de Talca en el fallo se deja constancia que el recurrente invocó la línea de unificación que nos interesa, pero al resolver la Corte de Apelaciones no se hace cargo de aquella y falla en un sentido diverso a lo que sostiene la Corte Suprema.

f. Unificación "Toro Cortes con Sociedad de Cobranzas Legales Lexicom Ltda. y Promotora CMR Falabella S.A.", rol 2392-2013, dictada el 14 de agosto de 2013 y que corresponde al RUC 12-4-0013029-7: Fue fallada en instancia el día 17 de julio de 2012 por el Primer Juzgado del Trabajo de Santiago y por la Corte de Apelaciones de Santiago el 12 de marzo de 2013. El tribunal de instancia no se hace cargo del criterio unificado para resolver el caso en contra de aquel y del contexto se deduce que la demandante planteó su defensa a partir de aplicación de doctrina del acto propio, para solicitar el rechazo de la existencia de relación laboral. Por su parte a la Corte de Apelaciones de Santiago se le hace ver, en uno de los recursos de nulidad, la línea en que se ha unificado el criterio y la Corte de Apelaciones para desestimar el recurso sostiene en su considerando 11 que "...en cuanto a la infracción al artículo 162 del Código del Trabajo por el hecho de que no existiría contrato de trabajo y de que la sanción de la nulidad del despido va dirigida en contra del empleador que bubiere descontado los montos correspondientes a las cotizaciones y no las bubiere enterado, esta Corte puede concluir que eso es una conclusión del actor ya que existe jurisprudencia en ambos sentidos, especialmente en cuanto si la sentencia que declara la existencia de una relación laboral es declarativa o constitutiva, por lo que no existirian las infracciones de ley denunciadas..." Se divisa de lo dicho por la Corte de Santiago es que el criterio unificado por la Corte Suprema vale tanto como los fallos de Cortes de Apelaciones que disienten de aquel, pues no hay jurisprudencia en ambos sentidos en la Corte Suprema desde que se unificó el criterio por primera vez.

${ }^{93}$ SCA Santiago, rol 1157-2012, 12 de marzo de 2013. 
Soto - ¿Criterios unificados como precedentes judiciales en materia laboral?...

iii) Casos de desalineamiento con criterio unificado relativos al articulo 45 del Código del Trabajo

El conjunto de fallos que se analiza giran sobre el problema jurídico de establecer, en el caso de trabajadores retribuidos con estipendio mixto (fijo y variable), si es requisito para que un estipendio variable sea base de cálculo que devengue diariamente.

La Corte Suprema desde el fallo "Prado Menares con ING AFP Capital S.A.", rol 6552-2010, de fecha 27 de enero de 2011 ha sostenido que “...los trabajadores incorporados en la parte final del inciso primero del artículo 45 del Código del Trabajo, afectos a un sistema remuneracional mixto, integrado por sueldo mensual $y$ remuneraciones variables, sólo tienen derecho al pago de la semana corrida, en la medida que sus remuneraciones variables sean devengadas dia a día, y en cambio no lo tienen, si tales remuneraciones se devengan en una unidad de tiempo distinta...".

Los fallos contrastados a este criterio son todos aquellos que fueron dictados por Juzgado del Trabajo y/o por Cortes de Apelaciones con posterioridad al 27 de enero de 2012 y que dieron lugar a una nueva unificación en la misma materia. Ellos son:

a. Unificación "Parada Mora con Administradora de Fondos de Pensiones Capital S.A.”, rol 10713-2011, dictada el 8 de agosto de 2012 y que corresponde al RUC 10-4-0041603-1: Fue conocida en instancia por el Segundo Juzgado del Trabajo de Santiago, el que dictó sentencia definitiva el 7 de enero de 2011. La Corte de Apelaciones de Santiago se pronunció en recurso de nulidad el 6 de octubre de 2011. Sin perjuicio que la sentencia del tribunal de instancia está fuera del rango temporal fijado, debemos mencionar que la parte demandada alegó que los trabajadores no tienen derecho a semana corrida porque sus estipendios no tenían la condición de devengo diario y al resolver el tribunal desestimó aquella alegación indicando que el devengo diario no era un requisito para tener derecho a semana corrida. Por su parte la Corte de Apelaciones rechaza el recurso de nulidad, en el que el demandado invoca la línea de unificación, sin hacerse cargo de señalar argumentos en contra de lo dicho por la Corte Suprema.

b. Unificación "Sindicato de Trabajadores Nutrabien S.A. con Alimentos Nutrabien S.A.", rol 7007-2012, dictada el 28 de enero de 2013 y que corresponde al RUC 12-4-0004722-5: Fue conocida y fallada por el Segundo Juzgado de Letras de Talagante el día 30 de mayo de 2012 y fue conocida por la Corte de Apelaciones de San Miguel, que falló recurso de nulidad el 1 de agosto de 2012. Al fallo del tribunal de instancia no se puede acceder vía web a la época de la realización del trabajo, sin embargo de la lectura de la sentencia 
que acoge el recurso de unificación se desprende que el tribunal de instancia rechazó otorgar la prestación de semana corrida. En cuanto al fallo de la Corte de Apelaciones, que conoce y acoge el recurso de nulidad de los demandantes, no se hace cargo del criterio unificado y sostiene que el devengo diario del estipendio remunerativo no es parte de los requisitos legales del artículo 45.

c. Unificación "Miranda Puelles con Empresa de Transportes Rurales Tur Bus Ltda.", rol 6673-2012, dictada el 23 de abril de 2013 y que corresponde al RUC 11-4-0017412-3: Fue conocida en instancia por el Segundo Juzgado de Letras del Trabajo de Santiago, quien la falló el 20 de julio de 2011. El recurso de nulidad fue resuelto por la Corte de Apelaciones de Santiago el 17 de julio de 2012. Corresponde por el límite de tiempo fijado revisar solo el fallo de la Corte de Apelaciones, porque respecto del fallo de instancia no había transcurrido un año desde la fijación del criterio unificado. La Corte para rechazar el recurso no entra a considerar el criterio unificado, sino que se centra en los defectos de fondo del recurso de nulidad deducido por la parte demandada.

d. Unificación "Moreno Salazar con CCTI S.A.", rol 7185-2012, dictada el 14 de marzo de 2013 y que corresponde al RUC 11-4-0016973-1: Dicha causa fue conocida por el Segundo Juzgado de Letras de Santiago, que la falló el 30 de julio de 2011 y por la Corte de Apelaciones de Santiago, la que conociendo del recurso de nulidad, se pronunció el día 9 de agosto de 2012. El fallo de instancia que concedió semana corrida está fuera del rango de tiempo a analizar. En cuanto a lo resuelto por la Corte de Apelaciones se puede indicar que la razón de rechazar el recurso de nulidad, y por ende mantener como válida la sentencia de instancia, no se relaciona con el criterio unificado ni es una cuestión sobre la que se razone, se desestima la nulidad por defectos en el planteamiento de las causales.

\section{f) Casos de desalineamiento de la Corte Suprema en relación con su criterio unificado:}

\section{i) Generalidades}

Nuestra investigación nos entregó dos casos en que la Corte Suprema habría variado su criterio unificado y de ellos uno es relevante para este trabajo, según se verá.

En el periodo analizado existe un caso anómalo, que debe ser mencionado. Respecto del criterio de unificación en cuya virtud los estipendios no remunerativos no integran la última remuneración, base de cálculo para 
Soto - ¿Criterios unificados como precedentes judiciales en materia laboral?...

indemnizaciones legales por término de contrato, que es sostenido de manera constante por la sala especial desde la unificación "Vega Montenegro con Análisis y Servicios S.A.”, rol 9603-2009. La extravagancia consiste en que en un fallo dictado por la sala de verano de la Corte Suprema, en marzo de 2012, en la causa "Henríquez, Leyton con Banco de Santiago", rol 7209-2011, se alteró el criterio unificado, pero la decisión se dio en recurso de casación en el fondo.

\section{ii) Aparente modificación en el criterio de decisión sobre la causal 5 del artículo 159 del Código del Trabajo}

El problema jurídico, sobre el que deciden los fallos que se analizarán, consiste en saber si es justificado aplicar la causal "de conclusión del trabajo o servicio que dio origen al contrato" a relaciones labores pactadas sin plazo definido y asociadas a la ejecución de un servicio que el empleador presta para un tercero, cuando el contrato entre el empleador y el tercero termina. La doctrina laboral ha entendido que aquello no se ajusta a derecho, pues lo que permite aplicar la causal es que se finalice el trabajo específico y determinado, señalado en el contrato de trabajo, $y$ para el cual fue contratado el trabajador. ${ }^{94}$

El primer fallo que se pronuncia sobre el particular, y que es además el primer recurso de unificación de jurisprudencia acogido, corresponde a la causa rol 2886-2009 "Ampuero Sánchezy otros con Agencia Marítima Alphamar S. A y Empresa Nacional del Petróleo".

a. Los actores demandaron se declarara injustificado su despido al haber aplicado su empleador la causal del artículo 159 número 5 del Código del Trabajo, quien la fundó en el término del contrato de Agenciamiento Marítimo Portuario que mantenía con Enap Magallanes.

b. El Primer Juzgado de Letras de Punta Arenas calificó los contratos de trabajo como indefinidos y acogió la demanda.

c. Recurrido el fallo de nulidad, la Corte de Apelaciones de Punta Arenas acogió el recurso, anuló la sentencia definitiva y dictó sentencia de reemplazo, en la que se declaró justificado el despido. Razonó la Corte de Apelaciones en el sentido que la concurrencia de la causal ya expuesta no se ve limitada o restringida por la naturaleza indefinida del contrato de trabajo, no existiendo impedimento alguno para ponerles término a los mismos aun cuando se trate de contratos por término indefinido, en los casos en que la obra o faena concluya por motivos ajenos al empleador que no constituyan un simple capricho o excusa, de tal suerte que es evidente que todo contrato de trabajo, incluso el de naturaleza indefinida, puede verse afectado por hechos externos a la

\footnotetext{
94 En este sentido Macchiavello (1986), pp. 494-499; THAYER y NOVOA (1998), pp. 39-40; LiZAMA (2003), pp.166-167; ROJAS (2004), pp. 242-243; LANATA (2009), pp.266-267.
} 
voluntad de las partes y no atribuibles al empleador como ocurrió en la especie.

d. Recurrido de unificación el fallo de la Corte de Apelaciones de Punta Arenas, la Corte Suprema expresó "Que se unifica la jurisprudencia en orden a que la causal establecida en el articulo $159 \mathrm{~N}^{\circ} 5$ del Código del Trabajo, resulta improcedente tratándose de contratos de naturaleza indefinida".

El segundo fallo corresponde al dictado en la unificación "Navarro Ponce con B.A.F. Servicios Integrales Ltda.", rol 3276-2010.

a. Los demandantes solicitaron la declaración de despido injustificado, al haber aplicado su empleador la causal del artículo 159 número 5 del Código del Trabajo, quien la fundó en el término del contrato de prestación de servicios que mantenía con el Hospital Carlos Van Buren, servicio para el cual se contrató a los trabajadores.

b. El Juzgado de Letras del Trabajo de Valparaíso acogió la demanda, entendiendo que los contratos de trabajo eran indefinidos y la causal, por tanto, injustificada.

c. Recurrido de nulidad el fallo instancia, la Corte de Apelaciones de Valparaíso rechazó anular, sosteniendo que no se puede confundir el contrato marco que celebró el empleador con el Servicio de Salud Valparaíso-San Antonio y los contratos de trabajo; y, que para aplicar la causal hay que atender al servicio contratado al trabajador; en dicho contexto el contrato de trabajo es indefinido y por tanto no procede emplear la causal aplicada, por lo que el juez actuó conforme a derecho y su sentencia es válida.

d. Recurrido de unificación, el precitado fallo que rechaza anular, la Corte Suprema recalificó los contratos de trabajo y estableció que estos no eran indefinidos, sino que por obra o servicio, y que por tanto la aplicación de la causal estaba ajustada a derecho y por ende correspondía rechazar la demanda.

Sin perjuicio que la discusión jurídica ronda sobre un problema similar, creemos que no existe formalmente un cambio de criterio jurídico, pues en el primer caso la discusión se centra en la aplicación de la causal a contratos de plazo indefinido, y por tanto no se discute que el contrato tenga tal naturaleza, en el segundo caso la disputa es si los contratos son indefinidos o son por obra o faena, y decidido lo segundo se entiende que el empleador aplicó correctamente la causal.

iii) Variación en el criterio de decisión sobre la aplicación de la sanción de ley Bustos a la empresa principal en hipótesis de trabajo en régimen de subcontratación

La cuestión de derecho, sobre los que versan los fallos que se analizarán, consiste en saber si legalmente la sanción contemplada en el artículo 162 del Código del Trabajo, consistente en la obligación de pagar remuneraciones post despido hasta el pago de las cotizaciones adeudadas a la fecha del mismo, es de aquellas 
Soto - ¿Criterios unificados como precedentes judiciales en materia laboral?...

obligaciones cubiertas por la responsabilidad solidaria o subsidiaria de la empresa principal, en el contexto de trabajo en régimen de subcontratación.

El primer fallo que se pronuncia sobre el punto corresponde a la causa rol 7502-2009 "Solís Jiménez. con Diseño Paisajista y Municipalidad de Calama".

a. El demandante dedujo demanda por despido indirecto, nulidad del despido y cobro de indemnizaciones y prestaciones laborales en contra de Diseño y Paisajista Limitada y, solidariamente, en contra de la Municipalidad de Calama.

b. El Juzgado de Letras del Trabajo de Calama acogió la demanda de despido indirecto, nulidad del despido y cobro de prestaciones laborales interpuesta; declaró, en lo que interesa, que al no haber enterado las cotizaciones previsionales del actor el despido indirecto es nulo y condenó a la demandada Diseño y Paisajista Limitada, al pago de las remuneraciones y demás prestaciones derivadas de la relación laboral, desde la fecha de término de esta hasta el pago efectivo de las cotizaciones previsionales atrasadas; en lo que se refiere a la Municipalidad de Calama, la condenó solidariamente a pagar al demandante los montos y conceptos a los que fue condenada la demandada principal.

c. La Municipalidad de Calama recurrió de nulidad alegando que la sanción del pago de remuneraciones y otras prestaciones, hasta convalidación del despido, no procedía en su contra por tratarse de la empresa principal.

d. Conociendo del recurso la Corte de Apelaciones de Antofagasta, acogió aquel recurso y dejó fuera de la responsabilidad de la Municipalidad, en tanto empresa principal, la responsabilidad del pago de remuneraciones y prestaciones hasta convalidación del despido.

e. La Corte Suprema conociendo recurso de unificación presentado por el demandante declaró que se unifica la jurisprudencia en el sentido que la empresa principal debe responder, solidariamente, de la condena impuesta a su contratista, por la infracción al artículo 162 del Código del Trabajo. Razonó en el sentido que límite temporal, que contempla la Ley $\mathrm{N}^{\circ}$ 20.123, al disponer que la responsabilidad solidaria estará limitada al tiempo o período durante el cual el o los trabajadores prestaron servicios en régimen de subcontratación para la empresa principal, no impide aplicar y extender los efectos de sanción del artículo 162 del Código Laboral, a la empresa principal en el ámbito de la responsabilidad solidaria que se le asigna.

El fallo que a nuestro juicio cambia el criterio de decisión al referido se encuentra en la sentencia de unificación dictada en los autos "Munizaga Morales con Factor Seguridad Limitada y Pre Unic", rol 9669-2011. 
a. El demandante interpuso denuncia de tutela de vulneración de derechos fundamentales con ocasión del despido y conjuntamente demanda de nulidad del despido y cobro de prestaciones en contra de Factor Seguridad Limitada y solidariamente o en forma subsidiaria en contra de Pre Unic S.A., solicitando se condene a las demandadas a pagar las prestaciones e indemnizaciones que señala, más intereses, reajustes y costas; ninguna de las demandadas contestó la demanda, ni compareció a la audiencias preparatoria y de juicio.

b. El tribunal de instancia, el Juzgado de Letras del Trabajo de Valparaíso, acogió la demanda interpuesta en cuanto declaró: I.- que el despido efectuado por Factor Seguridad Ltda. lo fue con vulneración de la garantía de indemnidad; II.- que el despido del actor es igualmente nulo, por lo que la demandada principal deberá pagar al demandante todas las remuneraciones, cotizaciones de seguridad social y demás prestaciones que se han devengado y se devenguen desde la separación ocurrida el 30 de agosto del año 2010, hasta la fecha en que la demandada convalide el despido; en lo que nos ocupa el fallo ordenó que la demandada Pre Unic S.A. debe pagar solidariamente las prestaciones asociadas a la nulidad de despido.

c. Pre Unic recurrió de nulidad en contra del referido fallo; en lo que nos interesa fundó el recurso en la causal prevista en el artículo 477 del Código del Trabajo en relación con los artículos 162 incisos quinto y séptimo y 183-B inciso primero del mismo cuerpo legal.

d. La Corte de Apelaciones de Valparaíso, conociendo del recurso de nulidad, lo rechazó considerando que no concurrían en la especie los vicios denunciados.

e. Contra el fallo de la Corte de Apelaciones de Valparaíso recurrió de unificación la demandada solidaria Pre Unic. La Corte Suprema conociendo el recurso de unificación lo acoge y declara que "...se unifica la jurisprudencia en el sentido que la sanción prevista para el empleador en los incisos quinto y séptimo del artículo 162 del Código del Trabajo, no es aplicable a la empresa principal o mandante, en su calidad de responsable solidaria o subsidiaria, pues aquélla es una norma sancionatoria o sustantiva, de derecho estricto $y$, por ende, de interpretación y aplicación restrictivas, y el régimen de responsabilidad aplicable al dueño de la obra o faena quedó regulado y minuciosamente acotado en el Título VII Párrafo $1^{\circ}$ del Libro I del citado Código, relativo al trabajo en régimen de subcontratación...". El criterio señalado se reitera en un fallo de unificación posterior. ${ }^{95}$

En el segundo fallo no se hace ninguna referencia a la primera doctrina que adoptó la Corte y actuó como si se tratara de un problema original. Es decir, se verifica en la especie que la Corte Suprema no siguió su criterio unificado y al cambiarlo no dio razones de la modificación

${ }^{95}$ SCS, rol 2500-2012, 28 de septiembre de 2012. 
Soto - ¿Criterios unificados como precedentes judiciales en materia laboral?...

\section{Conclusiones}

A la luz del trabajo podemos concluir:

a. Que en la dimensión de verticalidad, sobre la base de una noción moderada de precedente judicial vinculante y entregando un plazo suficientemente extenso (un año) para que el criterio unificado fuese socializado en los tribunales inferiores a la Corte Suprema, no resulta evidencia en orden a que los criterios unificados hayan operado, o constituido, como precedentes vinculantes en el sistema de enjuiciamiento laboral.

b. Que, en la misma dimensión, la falta de evidencia se hará más patente, si se establece como criterio de comparación una noción de precedente de mayor intensidad de vinculación.

c. Que, en la misma dimensión, la falta de evidencia también se hace más notoria según se disminuye el tiempo de socialización del criterio unificado.

d. Que, en la dimensión de auto precedente, la Corte Suprema ha tendido a sostener los criterios unificados cuando casos similares han llegado a su decisión.

e. Que, por último y en la misma dimensión de auto precedente, la Corte Suprema cuando ha variado su criterio unificado no ha dado cuenta de las razones de aquello. 


\section{BIBLIOGRAFÍA}

* AJANI, Gianmaria, ANDERSON, Miriam, ARROLLO, Esther y PASA, Bárbara (2010): Sistemas jurídicos comparados (Edicions Universitat Barcelona, Barcelona).

* BECERRA, Katherine (2013): "Rol del recurso de unificación de jurisprudencia en materia laboral: ¿Puede ser un configurador de precedente de los derechos fundamentales de los trabajadores?", en Arancibia Mattar, Jaime, Martínez Estay, José y Romero Seguel, Alejandro (Coord.) Precedente, cosa juzgada y equivalentes jurisdiccionales en la litigación pública (LegalPublishing/Thomson Reuters, Santiago), pp. 111-130.

* BIBlioteca DEL CONGRESO NACIONAL (2008): Historia de la Ley No 20.260.

* CUETO, Julio César (1997): El Common Law (Abeledo-Perrot, Buenos Aires).

* DAVID, René y JAUFFRET-SPINOSI, Camille (2010): Los grandes sistemas jurídicos contemporáneos (Centro Mexicano de Derecho Uniforme, Facultad Libre de Derecho de Monterrey, Monterrey), pp. 207, 212-230, 265-270.

* DELGADO, Jordi y DÍAZ GARCÍA, Iván (2011): "La unificación de jurisprudencia pretendida por el recurso extraordinario. Ventajas y problemas". en Revista de Derecho Universidad Católica del Norte (año 18, N²) pp. 275-304.

* DELGADO, Jordi (2011): "Examen crítico del recurso de unificación de jurisprudencia", en Revista de Derecho de la Pontificia Universidad Católica de Valparaíso (XXXVI).

* Real Academia Española (2001): Diccionario de la Lengua Española, 22 Edición, p. 1233.

* DWORKIN, Ronald (1992): El imperio de la justicia (Gedisa Editorial, Barcelona), p. 31.

* DUXBURY, Neil (2008): The nature and Authority of Precedents (Cambridge University Press, New York, Kindle Edition).

* GARNER, Bryan (Ed. (2004)): Black's Law Dictionary (8a edición, Thomson, St. Paul).

* HALIM, Fernando (2010): El recurso de unificación de jurisprudencia laboral (Thomson Reuters Puntolex, Santiago).

* HALPERN, Cecily y HUMERES, Héctor (2010): "La intervención de la Corte Suprema en la nueva justicia del trabajo: el recurso de unificación de jurisprudencia”, en Revista Actualidad Jurídica $\left(\mathrm{N}^{\circ} 21\right)$, pp. 345-374

* ITURRALDE, Victoria (2013): "El precedente judicial”, en Eunomía, Revista en Cultura de la Legalidad $\left(\mathrm{N}^{\circ} 4\right)$.

* LANATA, Gabriela (2009): Contrato individual de trabajo, $3^{a}$ edición, LegalPublishing, Santiago.

* (2011): El sistema de recursos en el proceso laboral cbileno, (LegalPublishing/AbeledoPerrot, Santiago).

* LARENZ, Karl (2001): Metodología de la Ciencia del Derecho (2 edición, Editorial Ariel, Barcelona).

* LIZAMA, Luis (2003): Derecho del Trabajo (Lexis Nexis, Santiago).

* LÓPEZ, Diego (2006): "El derecho de los jueces", en Revista Boletín Mexicano de Derecho Comparado (Legis Uniandes, Bogotá), p.3.

* MACCHiavello, Guido (1986): Derecho del Trabajo, tomo I (Fondo de Cultura Económica, Santiago).

* MERRYMAN, John Henry (2012): La tradición jurídica romano-canónica, $14^{a}$ reimpresión (Fondo de Cultura Económica, México D.F.).

* NINO, Carlos Santiago (1995): Introducción al análisis del derecho, 6a edición (Editorial Ariel, Barcelona).

* POSNER, Richard (1998): El análisis económico del derecho (Fondo de Cultura Económica, México D.F.). 
Soto - ¿Criterios unificados como precedentes judiciales en materia laboral?...

RÍOS, Lautaro (2013): "Reflexiones acerca del valor determinante del precedente en el sistema jurídico anglosajón y de la fuerza vinculante de la sentencia judicial en el nuestro", en Arancibia, Jaime, Martínez, José y Romero, Alejandro (Coord.): Precedente, cosa juzgada y equivalentes jurisdiccionales en la litigación pública (LegalPublishing/Thomson Reuters, Santiago).

* ROJAS, Irene (2004): Manual de Derecho del Trabajo (Lexis Nexis, Santiago).

* ROMERO, Alejandro (2004): La jurisprudencia de los tribunales como fuente del derecho (Una perspectiva procesal (Editorial Jurídica de Chile, Santiago).

(2011) "La discriminación judicial como nuevo error decisorio Litis en el proceso chileno", en Revista Chilena de Derecho (volumen 38, número 2), pp. 339-348.

(2013): El recurso de casación en el fondo civil (Propuestas para la generación de precedentes judiciales), (LegalPublishing/Thomson Reuters, Santiago).

* SÉROUSSI, Roland (1998): Introducción al Derecho inglés y norteamericano (Editorial Ariel, Barcelona).

* SILVA, Rodrigo (2006): Manual de procedimiento laboral (Análisis de la Ley No 20.087) (Editorial Jurídica de Chile, Santiago).

(2009) Manual de procedimiento laboral, $3^{a}$ edición actualizada (Editorial Jurídica de Chile, Santiago).

* TARUFFO, Michelle (2007): "Precedente y jurisprudencia", en Revista Precedente. Anuario Juridico de la Facultad de Derecho y Ciencias Sociales de la Universidad Icesi, pp.85-99.

* THAYER, William y NOVOA, Patricio (1998): Manual de derecho del trabajo, tomo III, $3^{\text {a }}$ edición (Editorial Jurídica de Chile, Santiago).

* WALTER, Rodolfo y LANATA, Gabriela (2007): Régimen legal del nuevo proceso laboral chileno (Estudio de las modificaciones introducidas por las leyes Nos20.022, 20.023 y 20.087) (LexisNexis, Santiago).

(2008) Régimen legal del nuevo proceso laboral chileno, $3^{\text {a }}$ edición (LegalPublishing, Santiago).

* YÁÑEZ, Eduardo (2010): "Unificación de jurisprudencia, precedente judicial y aplicación directa de la Constitución", en Revista Chilena de Derecho del Trabajo y de la Seguridad Social (volumen 1, número 2), pp.131-151. 